\title{
Chapter 25 \\ Maritime Operations and Emergency \\ Preparedness in the Arctic-Competence \\ Standards for Search and Rescue Operations \\ Contingencies in Polar Waters
}

\author{
Johannes Schmied, Odd Jarl Borch, Ensieh Kheiri Pileh Roud, \\ Tor Einar Berg, Kay Fjørtoft, Ørjan Selvik, and James R. Parsons
}

\begin{abstract}
Emergencies on large passenger ships in the remote High North may lead to a mass rescue operation with a heavy strain on the emergency preparedness systems of the Arctic countries. This study focuses on the need for competencies related to large-scale Search and Rescue operations (SAR operations) amongst the shipping companies, vessels and governments involved. A SAR operation is the activity related to finding and rescuing people in distress. Several international standards, in particular the conventions by the International Maritime Organization (IMO), provide direction for education and training of seafarers and rescue staff. This study elaborates on the operational competence requirements for key personnel involved in large scale SAR operations. Findings from real SAR incidents and exercises provide in-depth understanding on the operational challenges. The chapter gives directions for competence programs, beyond obligatory international standards, and recommendations for further research.
\end{abstract}

\footnotetext{
J. Schmied $(\bowtie) \cdot$ O.J. Borch • E.K.P. Roud

Nord University, Bodø, Norway

e-mail: johannes.schmied@nord.no; Odd.j.borch@nord.no; Ensieh.k.roud@nord.no

T.E. Berg • K. Fjørtoft • Ø. Selvik

SINTEF Ocean, Trondheim, Norway

e-mail: Tor.berg@sintef.no; kay.fjortoft@sintef.no; Orjan.selvik@sintef.no

J.R. Parsons

Memorial University of Newfoundland, St. John's, Canada

e-mail: jim.parsons@mi.mun.ca
} 


\subsection{Introduction}

The Arctic maritime regions are characterized by unique and challenging conditions including harsh weather, cold climate, remoteness from harbors and other infrastructure, and a vulnerable environment (Borch and Batalden 2015; Gudmestad et al. 1999; Løset et al. 1999). Incidents involving vessels with many people on board are among the most challenging emergencies to prepare for and to prevent (Ho 2010; Marchenko et al. 2015; Lasserre and Pelletier 2011).

Regional authorities in several Arctic areas including the Northern Sea Route, the North West Passage, and the Spitsbergen region may experience severe capacity and competence challenges in case of an accident involving passenger ships, due to the larger passenger numbers on the vessels and the limited resources available (Arctic Council 2009; Johnston et al. 2012; Roud et al. 2016). An emergency on a cruise ship may have severe consequences (Lois et al. 2004; Vanem and Skjong 2004) as highlighted in the Costa Concordia accident. Several related key challenges may emerge including SAR, fire-fighting, oil recovery operations and vessel salvage.

Regulations such as the International Code for Ships Operating in Polar Waters (Polar Code) may reduce the probability of large scale accidents and increase preparedness on board the vessels (Jensen 2016; Bai 2015). Governments may demand special competence and pilots onboard, and also restrict access to challenging sea regions.

However, there is a risk for severe accidents (Marchenko et al. 2015). Regional studies have shown limitations in SAR capacities, including the SAR technology adapted to the region. This includes information and communication tools for remote areas such as Single Window (Fjortoft et al. 2011), innovation in Arctic vessel and rescue equipment (Berg et al. 2013; Gudmestad and Karunakaran 2012; Torheim and Gudmestad 2011) and development of Arctic infrastructure (Dodds 2013). There is a need for operational knowledge, especially on cooperation among the broad range of actors involved in major accidents, including the crew of the vessel in distress, joint rescue coordination centers (JRCC), coast guard, private preparedness organizations, Samaritan vessels, police, the ship owners and their stakeholders (Borch and Andreassen 2015).

Differences in organization and management principles of stakeholders within emergency networks may hamper partnership and cooperation across institutions and borders. Recently, the Incident Command System (ICS) has gained importance in the response management structure of Arctic states such as the USA, Canada and Norway (Bigley and Roberts 2001). However, other actors such as the NATO military organizations apply other systems with a different management structure. For example, in Norway the police and the military apply their management structure, while the fire and rescue brigades and oil recovery authorities have introduced ICS into their operations (The Roksund Government Committee 2016).

In this respect, there is a need to look closer into the actual roles and positions of operators along the SAR value chain. As an example, the supportive organization and the competence of the on-scene commanders have not been thoroughly studied 
in the context of Arctic remoteness and mass rescue scenarios (Borch and Andreassen 2015; Małyszko and Wielgosz 2016).

This chapter discusses how the competence of key Arctic maritime SAR personnel needs to be developed in order to manage incidents involving multiple emergency services with different modes of operation. Competence requirements are elaborated upon, both at the operational coordination and command level as well as at the local on-scene tactical level.

Only a few studies have focused on the role of maritime SAR-leaders. Crichton et al. (2005) reflect on incident command skills on oil platforms with respect to the five categories of situational awareness, decision-making, teamwork, leadership and communication. Borch and Andreassen (2015) emphasize the roles of emergency preparedness managers.

Creating common situational awareness is the critical first part of any SAR operation. Knowing what is going on is one of the key prerequisites in crisis response (Oomes 2004; Endsley and Garland 2000). However, areas like the Arctic are prone to limited information and situational awareness due to limited communication facilities (Behlke 2013), lack of vessels and equipment, as well as personnel (Berg et al. 2013; Borch and Andreassen 2015; Rottem 2014). The capability to make decisions based on limited knowledge may improve through education. Klein (1993), Orasanu and Connolly (1993), Cosgrave (1996) and Dreyfus and Dreyfus (1986) claim that the ability to assess situations can be improved through practiced understanding - in other words exercises and training.

Decision making in a SAR value chain is a difficult command skill and characterized by uncertainty about the cause-consequence links, due to limited information and knowledge as to both context and SAR-tools available (Liu et al. 2014). One aspect, which is particularly highlighted in recognition-primed decision model and naturalistic decision-making (Liu et al. 2014), is the importance of previous events or training and exercises, which enforces the importance of having experienced and suitably trained decision makers. According to both the incident command approach by Crichton et al. (2005) and Managerial Roles by Mintzberg (2009), a broad range of leadership tasks plays a central role in managing demanding situations.

Due to the scale of a mass rescue operation compared with the lack of immediate resources available, close cooperation and teamwork amongst several organizations is needed. Trust between the organizations is important. Sako (1998) suggests that trust can be based on the trustee establishing competence, goodwill or contractual promise keeping. The trustor on the other hand becomes vulnerable to the trustee's actions (see Wilson et al. 2007).

Specifically, contractual trust may include standard operation procedures (SOP) which frame teamwork (Ivanova 2011; Ivanova and Sydnes 2010; Sydnes and Sydnes 2013). A continuous information flow via SOPs may enable more efficient use of resources, coordination and lower risk of operations, possibly at all levels from the operational scene up to the national government level. Interpersonal communication hereby plays a major role (Mintzberg 2009).

Finally, competence based on communication and communication systems is highly important and needs to be established prior to potential incidents (Crichton 
et al. 2005; Kapucu et al. 2010). Communication may already be compulsory due to pre-existing control mechanisms (Mintzberg 2009). Yet, aspects such as lack of trust due to cultural or political reasons or different language, be it due to different standards in different institutions or different nationalities, may be critical aspects of communication (Comfort and Kapucu 2006; Kapucu 2005; Robinson et al. 2015). In a case study of a SAR-exercise focusing on shared situational awareness and communication, Seppänen et al. (2013) discovered that "information gaps, the lack of fluent communication, and the fact that there is no common operational picture" hamper emergency management.

SAR operations at sea are regulated by, among others, the International Convention on Maritime Search and Rescue (SAR), International Aeronautical and Maritime Search and Rescue (IAMSAR)-Manuals 1-3 and the International Convention for the Safety of Life at Sea (SOLAS). SOLAS includes the relevant International Ship and Port Facility Security Code (ISPS-Code). Additional regulatory framework includes the International Convention on Standards of Training, Certification and Watchkeeping for Seafarers (STCW) with the Manila amendments of 2010, the International Convention on Standards of Training, Certification and Watchkeeping for Fishing Vessel Personnel (STCW-F), as well as other IMO conventions with indirect relevance to SAR and standards by standardization societies. With respect to cross-boundary coordination and host nation support (HNS) the United Nations Law of the Sea (UNCLOS) and regional and bilateral agreements on responsibility, rights and exercises are important.

A study by Ghosh and Rubly (2015) supports the importance of the Polar Code, pointing out that emergency management personnel including the on-scene staff such as captains, officers and crew, need to understand and be able to handle potential hazards and risks. Sander et al. (2015) point out the need for further regulations. Even though the Polar Code provides regulations to a certain extent, Jensen (2016) questions the potential power of the Polar Code due to its openness to national interpretation with regard to implementation standards.

The IAMSAR Manuals define the on-scene coordinator (OSC) as the most capable and trained leading person on site (IMO 2016). According to Rake and Njå (2009), the OSC needs to be well-rendered, aware of the situation, a good communicator, quick at information processing, a quick decision maker and swift at improvising. The OSC has to be clear, available, cooperative and lead with authority. Also the OSC has to have best suitable equipment and support from the JRCC (see Małyszko and Wielgosz 2016; Ansell et al. 2010).

The IAMSAR manuals of 2016 for the first time also establish the Aircraft Coordinator (ACO) in an equally important manner as the OSC (IMO 2016). The ACO should maintain high flight safety, advise and support as well as increase effectiveness of the operation (Ibid; USCG 2010). Few systematic studies related to marine ACO competence have been found.

A facilitating Command System is also essential for successful emergency response. It is traditionally structured hierarchically and has clear command and control agreements (Owen et al. 2015). Particularly ICS are designed for large-scale operations and support coordination, flow of information, best possible use for on-scene personnel and timely decision making (Rimstad et al. 2014; Boersma et al. 2014). 
Rimstad et al. (2014) claim that crises should be managed at the lowest possible level, procedures should be every day procedures, and both public and private actors should jointly provide all resources available. Yet, there is a need for mission commanders to coordinate and facilitate cooperation beyond organizations and borders (Politidirektoratet 2011). Christensen et al. (2012) show that information flow and mobilization should run as automatically and efficiently as possible and observe increased vertical information flows within an organization, before information is shared horizontally.

By keeping the complexity and uncertainty of Arctic maritime emergency operations in mind, there is a special challenge related to the role of the emergency system managers and their command structure. There is a need to develop a look into criteria for relevant command skills and competences for on-scene personnel and the command system, and to find the tools needed for education and training of key personnel along the whole SAR-value chain.

\subsection{Methods}

This study followed an in-depth, qualitative research strategy focusing on command structures, managerial roles and the emergency management competence needs. Illustrative cases were chosen to highlight the complexity and challenges of SAR operations in Arctic waters.

Data were collected from observations both on full scale and table top exercises (TTX). The observational studies were followed up by unstructured interviews with key personnel after the SAR exercises. In addition, a combination of interviews, studies of logs and investigation reports from major accidents were included.

The study follows up on eleven cases (Table 25.1) taken from a larger research initiative with 27 cases. Both domestic and international exercises were included in the study to emphasize the challenges in organizational- and cross-border cooperation. Related standards and regulations in the Arctic were reviewed and reflected upon according to data from exercise observations. In the analysis, the data from exercises and incidents were screened on competence gaps and challenges in order to determine further necessary activity to develop relevant command skills and competences for on-scene personnel and the command system.

\subsection{Results and Discussion}

In a mass rescue operation the number of persons in the water, in rafts and in life boats may be overwhelming. There may also still be people on board the vessel in distress. Real incidents like the Maxim Gorkiy collision with ice in the Spitsbergen region and the Costa Concordia grounding in Italy showed that a major challenge in mass rescue incidents is to perform "vessel or rescue unit triage" i.e. prioritize who 
Table 25.1 List of exercises and incidents presented in this study

\begin{tabular}{l|l|l|l|l|l}
\hline Name & Exercise/incident/other & Year & Month & Place & Documents \\
\hline $\begin{array}{l}\text { Maxim } \\
\text { Gorkiy }\end{array}$ & Incident & 1989 & June & Svalbard & $\begin{array}{l}\text { Logs, reports, } \\
\text { articles, case } \\
\text { study, interview }\end{array}$ \\
\hline $\begin{array}{l}\text { Costa } \\
\text { Concordia }\end{array}$ & Incident & 2012 & January & Italy & Report \\
\hline $\begin{array}{l}\text { KV SAR } \\
2016\end{array}$ & $\begin{array}{l}\text { Newsletter on exercises } \\
\text { and incidents }\end{array}$ & $2015 / 16$ & Several & Norway & Summary \\
\hline $\begin{array}{l}\text { Barents } \\
\text { Rescue } \\
\text { exercise }\end{array}$ & Full scale exercise & 2015 & September & Finland & Observation \\
\hline $\begin{array}{l}\text { Exercise } \\
\text { Barents }\end{array}$ & TTX/Full scale exercise & $2015 / 16$ & Several & Barents & $\begin{array}{l}\text { Observation, } \\
\text { protocol, brief }\end{array}$ \\
\hline $\begin{array}{l}\text { Exercise } \\
\text { Helgeland }\end{array}$ & Full scale exercise & 2015 & May & Norway & $\begin{array}{l}\text { Log book, } \\
\text { observation, } \\
\text { protocol }\end{array}$ \\
\hline $\begin{array}{l}\text { Exercise } \\
\text { Nord }\end{array}$ & Full scale exercise & $2015 / 16$ & April & Norway & Log book \\
\hline $\begin{array}{l}\text { TTX KV } \\
\text { Sortland }\end{array}$ & Table top exercise & 2016 & April & Norway & Brief, log-book \\
\hline $\begin{array}{l}\text { SARex } \\
\text { Full scale exercise }\end{array}$ & 2016 & April & Svalbard & $\begin{array}{l}\text { Observation, } \\
\text { log books, } \\
\text { reports }\end{array}$ \\
\hline $\begin{array}{l}\text { Arctic } \\
\text { SAR }\end{array}$ & Meta table top exercise \\
$\begin{array}{l}\text { AECO } \\
\text { SAR } \\
\text { arkshop }\end{array}$ & Table top exercise & 2016 & April & $\begin{array}{l}\text { Video } \\
\text { Conference }\end{array}$ & $\begin{array}{l}\text { Observation, } \\
\text { protocol, } \\
\text { summary }\end{array}$ \\
\hline
\end{tabular}

to rescue based on limited information. This is especially a challenge for on-scene personnel. It also lays a heavy burden on the mission coordinator at the JRCC, who may experience challenges to allocate adequate resources fast enough.

In the Arctic, helicopter resources may play a vital role especially in an early phase. The Air Coordinator role is also reported to become more demanding in mass rescue incidents and needs further exercise and training with respect to the IAMSAR manuals (see IMO 2016). Exercise Nord and Arctic SAR indicated that airborne professionals and SAR non-professional captains, officers and masters are often first on-site and therefore need to be well-educated for the OSC-role (see Klein 1993; Orasanu and Connolly 1993; Cosgrave 1996; Dreyfus and Dreyfus 1986).

Therefore, more specific training and development for potential ACOs and OSCs is in demand. In the TTX KV Sortland it was discussed to assign this task to a person that could also fill the figurehead-role, as described by Mintzberg (2009).

The importance of crew situational awareness, spontaneous adaptation to changes and knowledge on procedures, standards and automated processes were highlighted by the reports of the Costa Concordia incident. In this case, crew train- 
ing on passenger management would have been particularly beneficial to prevent casualties. The Polar Code's chapter "Manning and Training" discusses these tasks, albeit on a rather general level. As a consequence, the IMO is working on stricter procedures in this respect.

For the master of the distress vessel and the on-scene coordinator, knowledge gathering and operational planning for the steps ahead including improvisation was important, but seldom trained at a realistic scale (source: Exercise SARex and Exercise Nord). Periodic dialogue and data sharing as well as training with the SAR operators and the JRCC on resource allocation and priorities are critical in this respect.

Experience from Exercise Barents 2015 showed that in some cases, difficult political situations or heavily bureaucratic bilateral cooperation is reducing the effects of the exercise. Knowledge and testing of the underlying Arctic SAR control mechanisms are recommended for improvement. Further efforts to increase awareness and competence in the command system in terms of cross border cooperation and HNS may include a "written brief on the structure of the host nation's command system", as recommended from the Barents Rescue exercise 2015.

Preparation of ships before they go to the Arctic may help captains in case of emergencies. Not the least, the importance of fast alarm is central. The Costa Concordia and Maxim Gorkiy incidents are two examples where alarms came more than an hour after the accident. Furthermore, harbors and their crew need to adapt to increased ship sizes and activities and be prepared for taking care of a large number of rescued persons (Haugen and Fjortoft 2011). Decision support systems, as suggested by Małyszko and Wielgosz (2016), may help to determine methods for managing all these data and make decisions under uncertainty. Also, the establishment and preparation of action plans helped both the OSC as well as the whole command system to perform efficiently (Report from Exercise Helgeland on oil spill recovery).

In this respect, it is vital to know and efficiently communicate where the responsibilities of each person (OSC, ACO, Captain, Samaritan Vessels, etc.) start and end. Taking care of OSC responsibilities may demand several persons, and how to choose them is not elaborated upon in the IAMSAR manuals (IAMSAR Volume II). Actors should be aware of differences and regulations of the control mechanisms and, in turn, commit to trust, as outlined by Sako (1998).

Regardless of the field of research, researchers agree on the importance of trust in social interaction (Rousseau et al. 1998). Data from domestic exercises and the AECO SAR workshop showed that those who had developed relations prior to the actual emergency response through daily collaboration had built trust, and thus experienced fewer challenges in organizational collaboration on complex tasks. This includes willingness to collaborate, information sharing and shared values or standards (see Kapucu 2006).

Preparedness of the vessel's communication lines and competence in use is crucial. Connection capacities may be limited in the Arctic, as discussed previously, causing decision-making under ambiguity (Behlke 2013). Preparations and installations before a cruise journey (e.g., via Polar Water Operational Manual), including actual learning from the experiences of previous cruises is therefore important. 
In order to support communication, chat systems and shared written communication logs have proven to be an efficient tool for command systems to overcome misunderstandings resulting from oral communication. However, as was indicated in the Norwegian Coast Guard SAR info KV 2016, it is at times still problematic with different chat-programs, different cultures and un-coordinated systems, especially in terms of larger incidents including several command structures or crossborder response. More communication capacity has therefore been requested during exercises between the OSC and HNS resources.

\subsection{Conclusions}

The objective of this study was to provide insights into the roles of the emergency command system. Arctic SAR operations and especially mass rescue operations are very complex and require enhanced experience from the key personnel. The Polar Code will contribute to increased crew and operator knowledge on the unique conditions of the Polar regions, including what is needed as to safety training and manning for emergency situations. Efficient communication and close interaction between the vessel in distress, the OSCs and the SAR mission coordinators are vital, and should be emphasized in all procedures.

This study has shown that exercises are often too limited in scale and scope and do not illuminate the full range of challenges related to mass rescue operations in the Arctic. Advanced OSC courses should be available for a broader spectrum of personnel including the masters and officers of all vessels in Polar regions who are often the first on site. For vessel captains, additional course modules in the Global Maritime Distress and Safety System course on OSC/ACO-air coordinator roles in the Arctic need to be developed as well as integrated in the Polar water operation manuals and contingency plans. This is particularly important for the crew of large passenger vessels operating in remote areas.

The results of this study indicate that immediate alarm notification and creation of a common situational awareness are key issues induced by the operational knowledge. In mass rescue incidents the leading personnel both on board and on shore, including the OSC, ACO, SAR mission coordinator and staff need to be aware of the capabilities and capacities that may be mobilized in different phases of the emergency. More efforts towards competence sharing are recommended in all stages of the SAR value chain. The operators on different levels need in-depth education on decision making under uncertainty, teamwork and leadership. Cross-institutional cooperation in education may help to pinpoint the bottlenecks within the command systems and reveal opportunities on how to integrate different systems.

Further studies on the coordination of cross-institutional cooperation, managerial roles, competence sharing and the trust aspect may contribute to increased efficiency in joint actions within the Arctic SAR value chain. 


\section{References}

Ansell C, Boin A, Keller A (2010) Managing transboundary crises: Identifying the building blocks of an effective response system. J Conting Crisis Manag 18(4):195-207

Arctic Council (2009) Arctic marine shipping assessment (AMSA). PAME and Arctic Council, Oslo

Bai J (2015) The IMO Polar Code: The emerging rules of Arctic Shipping Governance. Int J Mar Coast Law 30(4):674-699

Behlke R 2013 Maritime user requirements on navigation and communication solutions at high latitudes (Svalbard)-with an outlook on the MARENOR project. In: AGU Fall Meeting Abstracts. p 2242

Berg TE, Holte EA, Ose GO, Færevik H (2013) Safety at Sea: Improving Search and Rescue (SAR) Operations in the Barents Sea. In: ASME 2013 32nd International Conference on Ocean, Offshore and Arctic Engineering. American Society of Mechanical Engineers, pp V006T007A007-V006T007A007

Bigley GA, Roberts KH (2001) The incident command system: High-reliability organizing for complex and volatile task environments. Acad Manag J 44(6):1281-1299

Boersma K, Comfort L, Groenendaal J, Wolbers J (2014) Editorial: Incident command systems: A dynamic tension among goals, rules and practice. J Conting Crisis Manag 22(1):1-4

Borch OJ, Andreassen N (2015) Joint-task force management in cross-border emergency response. Managerial roles and structuring mechanisms in high complexity-high volatility environments. information, communication and environment: marine navigation and safety of sea transportation: 217

Borch OJ, Batalden B-M (2015) Business-process management in high-turbulence environments: the case of the offshore service vessel industry. Marit Policy Manag 42(5):481-498

Christensen T, Lægreid P, Rykkja LH (2012) How to cope with a terrorist attack?-a challenge for the political and administrative leadership. COCOPS working paper 6

Comfort LK, Kapucu N (2006) Inter-organizational coordination in extreme events: The World Trade Center attacks, September 11, 2001. Nat Hazards 39(2):309-327

Cosgrave J (1996) Decision making in emergencies. Disaster Prev Manag 5(4):28-35

Crichton MT, Lauche K, Flin R (2005) Incident command skills in the management of an oil industry drilling incident: A case study. J Conting Crisis Manag 13(3):116-128

Dodds KJ (2013) Anticipating the Arctic and the Arctic Council: pre-emption, precaution and preparedness. Polar Record 49(02):193-203

Dreyfus H, Dreyfus S (1986) Mind over machines. Mind over machines

Endsley MR, Garland D (2000) Theoretical underpinnings of situation awareness: A critical review. Situation awareness analysis and measurement:3-32

Fjortoft K, Hagaseth M, Lambrou M, Baltzersen P, Papachristos D, Nikitakos N (2011) Maritime transport single windows: issues and prospects. Transport systems and processes: Marine navigation and safety of sea transportation: 19

Ghosh S, Rubly C (2015) The emergence of Arctic shipping: issues, threats, costs, and riskmitigating strategies of the Polar Code. Aust J Maritime and Ocean Aff 7(3):171-182

Gudmestad O, Zolotukhin A, Ermakov A, Jakobsen R, Michtchenko I, Vovk V, Løset S, Shkhinek $\mathrm{K}$ (1999) Basics of offshore petroleum engineering and development of marine facilities. Oil and Gas Printing House, Moscow, pp 176-196

Gudmestad OT, Karunakaran D (2012) Challenges faced by the marine contractors working in western and southern Barents Sea. In: OTC Arctic technology conference. Offshore Technology Conference

Haugen T, Fjortoft K (2011) Visions and future needs in Arctic Maritime Operations

Ho J (2010) The implications of Arctic sea ice decline on shipping. Mar Policy 34(3):713-715

IMO (2016) IAMSAR Manual II - Mission Co-ordination. ISBN: 978-92-801-1640-3

Ivanova M (2011) Oil spill emergency preparedness in the Russian Arctic: a study of the Murmansk region. Polar Res 30

Ivanova M, Sydnes AK (2010) Interorganizational coordination in oil spill emergency response: a case study of the Murmansk region of northwest Russia. Polar Geogr 33(3-4):139-164 
Jensen $\varnothing$ (2016) The international code for ships operating in polar waters: finalization, adoption and law of the sea implications. Arctic Rev on Law and Politics 7(1):60-82

Johnston A, Johnston M, Stewart E, Dawson J, Lemelin H (2012) Perspectives of decision makers and regulators on climate change and adaptation in expedition cruise ship tourism in Nunavut. Northern Review (35)

Kapucu N (2005) Interorganizational coordination in dynamic context: Networks in emergency response management. Connections 26(2):33-48

Kapucu N (2006) Interagency communication networks during emergencies boundary spanners in multiagency coordination. Am Rev Public Adm 36(2):207-225

Kapucu N, Arslan T, Demiroz F (2010) Collaborative emergency management and national emergency management network. Disaster Prevention and Management: An International Journal 19(4):452-468

Klein GA (1993) A recognition-primed decision (RPD) model of rapid decision making. Ablex Publishing Corporation, New York

Lasserre F, Pelletier S (2011) Polar super seaways? Maritime transport in the Arctic: an analysis of shipowners' intentions. J Transp Geogr 19(6):1465-1473

Liu Y, Fan Z-P, Yuan Y, Li H (2014) A FTA-based method for risk decision-making in emergency response. Comput Oper Res 42:49-57

Lois P, Wang J, Wall A, Ruxton T (2004) Formal safety assessment of cruise ships. Tour Manag 25(2009):93-109

Løset S, Shkhinek K, Gudmestad O, Strass P, Michalenko E, Frederking R, Kärnä T (1999) Comparison of the physical environment of some Arctic seas. Cold Reg Sci Technol 29(3):201-214

Małyszko M, Wielgosz M (2016) Decision support systems in search, rescue and salvage operations at sea. Sci J Maritime Univ Szczecin 45(45):191-195

Marchenko NA, Borch OJ, Markov SV, Andreassen N (2015) Maritime activity in the high North the range of unwanted incidents and risk patterns. Proceedings of the 23rd international conference on port and ocean engineering under arctic conditions (June 14-18, 2016)

Mintzberg H (2009) Managing. Berrett-Koehler Publishers, San Francisco

Oomes A (2004) Organization awareness in crisis management. In: Proceedings of the international workshop on information systems on crisis response and management (ISCRAM)

Orasanu J, Connolly T (1993) The reinvention of decision making

Owen C, Scott C, Adams R, Parsons D (2015) Leadership in crisis: developing beyond command and control. Aust J Emerg Manag 30(3): 15

Politidirektoratet (2011) PBS I - Politiets BEREDSKAPSSYSTEM del I - Retningslinjer for politiets beredskap. POD-publikasjon nr. 2011/04

Rake EL, Njå O (2009) Perceptions and performances of experienced incident commanders. J Risk Res 12(5):665-685

Rimstad R, Njå O, Rake EL, Braut GS (2014) Incident Command and Information Flows in a Large-Scale Emergency Operation. J Conting Crisis Manag 22(1):29-38

Robinson JJ, Maddock J, Starbird K (2015) Examining the role of human and technical infrastructure during emergency response. In: Information systems for crisis response and management, ISCRAM

Rottem SV (2014) The Arctic Council and the search and rescue agreement: the case of Norway. Polar Record 50(03): 284-292

Roud EKP, Borch OJ, Jakobsen U, Marchenko N (2016) Maritime emergency management capabilities in the Arctic. In: Proceedings of the twenty-sixth (2016) international ocean and polar engineering conference. International Society of Offshore \& Polar Engineers

Rousseau DM, Sitkin SB, Burt RS, Camerer C (1998) Not so different after all: A cross-discipline view of trust. Acad Manag Rev 23(3):393-404

Sako M (1998) Does trust improve business performance. Organizational trust: A Reader:88-117

Sander G, Gille J, Stępień A, Koivurova T, Thomas J, Gascard J-C, Justus D (2015) Changes in Arctic maritime transport. In: The changing arctic and the European union. Brill, p 81-114 
Seppänen H, Mäkelä J, Luokkala P, Virrantaus K (2013) Developing shared situational awareness for emergency management. Saf Sci 55:1-9

Sydnes AK, Sydnes M (2013) Norwegian-Russian cooperation on oil-spill response in the Barents Sea. Mar Policy 39:257-264

The Roksund Government Committee (2016) The Roksund working group on armed forces support to the police (in Norwegian: Forsvarets Bistand til Politiet - Rapport fra arbeidsgruppen for utarbeiding av forslag til ny bistandsinstruks). ISBN: 978-82-7924-088-4, vol 09/2016 - opplag 100. Norwegian Ministry of Justice and Public Security, Available at: https://www.regjeringen. no/globalassets/departementene/fd/dokumenter/rapporter-og-regelverk/20160930-rapport-fraarbeidsgruppen-for-utarbeiding-av-forslag.pdf

Torheim S, Gudmestad OT (2011) Secure launch of lifeboats in cold climate: looking into requirements for winterization. In: ASME 2011 30th international conference on ocean, offshore and arctic engineering. American Society of Mechanical Engineers, pp 931-939

USCG (2010) International manual for aircraft coordinator. Available at: https://www.uscg.mil/hq/ cg5/cg534/nsarc/BalticAcoManual.pdf

Vanem E, Skjong R (2004) Collision and grounding of passenger ships-risk assessment and emergency evacuations. In: Third international conference on collision and grounding of ships (ICCGS). p 202

Wilson KA, Salas E, Priest HA, Andrews D (2007) Errors in the heat of battle: Taking a closer look at shared cognition breakdowns through teamwork. J Human Factors Ergon Soc 49(2):243-256

Open Access This chapter is licensed under the terms of the Creative Commons Attribution 4.0 International License (http://creativecommons.org/licenses/by/4.0/), which permits use, sharing, adaptation, distribution and reproduction in any medium or format, as long as you give appropriate credit to the original author(s) and the source, provide a link to the Creative Commons license and indicate if changes were made.

The images or other third party material in this chapter are included in the chapter's Creative Commons license, unless indicated otherwise in a credit line to the material. If material is not included in the chapter's Creative Commons license and your intended use is not permitted by statutory regulation or exceeds the permitted use, you will need to obtain permission directly from the copyright holder.

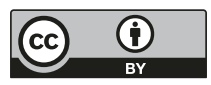

